\title{
A Study on Mobile Easy Payment Service Based on FinTech to Reduce Smart Divide and Income Gap
}

\author{
Hong Jae Lee ${ }^{1}$ and Kyeong Seok Han ${ }^{2 *}$ \\ ${ }^{1}$ PhD in Engineering, Soongsil University, Seoul, CEO of Smartro Co., Ltd., Seoul \\ $2^{2}$ Professor of MIS, School of Business Administration, Soongsil University, Seoul \\ ${ }^{1} h j l e e 15314 @ d a u m . n e t,{ }^{2}$ kshan@ssu.ac.kr
}

\begin{abstract}
With the spread of smart devices connected to the Internet anytime and anywhere, FinTech-based mobile easy payment services are emerging in commerce and consumption activities. In order to realize a cashless society, each country adopts mobile payment method as its main policy objective. It is actively promoting regulations and alleviating regulations. This is a very important task. Since the mobile easy payment services are still in the infancy phase, it is being investigated that the acceptance rate among the layers is various. Through previous researches, it was confirmed that the most important factor affecting the intention of using mobile easy payment service was perceived usefulness, and the factors influencing perceived usefulness were classified as personal characteristics, service characteristics, environmental characteristics and service characteristics. The purpose of this study is to investigate whether people with experience using mobile easy payment service will continue to use the service in the future and what factors influence the intention to use the service continuously. The results of the study showed that the variables of personal characteristics and service characteristics influenced the intention to use continuously in the future through perceived usefulness. In addition, it has been found that the various gaps between the layers are important factors in the future intention of mobile payment service. According to the results of this study, the important national task in spreading mobile payment service is suggesting that how to resolve the smart divide and the income gap is an important policy task.
\end{abstract}

Keywords: FinTech, Mobile Easy Payment Service, TAM, Smart divide, Income divide

\section{Introduction}

With the spread of smart devices connected to the Internet anytime and anywhere in the world, various forms of business have emerged and new forms of change are taking place in all areas such as public service, education, media, commerce, and finance. Innovative changes have emerged over time. In particular, innovative business models based on FinTech have emerged in commerce and consumption activities that make up a large part of our lives, leading innovation in finance, shopping, and payment [13]. The change of existing financial services provides new services such as mobile network, social network service, and big data by utilizing new IT technology. In addition, the number of users and the usage rate in the payment market have been rapidly increasing due to the proliferation of smartphones and the competition for service innovation among providers of payment services.

So far, the research on mobile easy payment service has shown that the introduction period of the service is only $2 \sim 3$ years recently, so there is not a lot of research result in the first place. Mobile easy payment services are becoming innovative and diverse, and

Received (January 4, 2018), Review Result (March 8, 2018), Accepted (March 12, 2018)

${ }^{*}$ Corresponding Author 
their use is complex. In the previous studies, the classification and definition of the easy payment service were often uncertain

The purpose of this study is to clarify the types and characteristics of various mobile easy payment services based on FinTech and to analyze the correlation and characteristics of the factors that affect the intention of continuous use of mobile easy payment service. The basic question of this study is whether those who have experience using mobile easy payment service will continue to use the service in the future and what factors will affect the intention to use continuously. I want to know what it is.

\section{Theoretical Background}

\subsection{Concept of FinTech}

FinTech is a combination of finance, which means finance, and technology, which means technology. It is not meant to provide IT services for the convenience of existing financial companies. This means providing financial services and providing new types of financial services by utilizing the inherent security of the company $[10,16]$.

As the spread of smartphones has become popular recently, FinTech is providing different and practical FinTech financial services such as landing, platform, big data, cloud funding, easy payment and remittance service. The FinTech industry has been rapidly growing because of the spread of smartphones and the rapid development of communication, and since 2009 the open wireless Internet network has spread and the social infrastructure for activation has been established.

\subsection{FinTech-based Mobile Easy Payment Service}

The mobile easy payment service allows you to register your credit card, check card, account transfer, and mobile phone payment information using your smartphone application. Can be done [11]. It is a payment service that allows a user to securely make a payment if the authentication is completed. At this time, the payment information such as the card number registered by the user is encrypted in the electronic payment service agency, and the information is retrieved when the payment is made [9]. There is a slight difference between services, but I do not use Active $X$ that I installed. In addition, the electronic payment and payment agency stores payment information, and it has a feature of paying by authentication only through the private password of the payment means [12].

\subsection{Technology Acceptance Model}

The TAM (Technology Acceptance Model) presented perceived ease of use and perceived usefulness as important variables influencing individual acceptance of information technology [8]. The external variables influence perceived usefulness and perceived ease of use, and these two variables influence the attitude toward the use of information technology, which affects the intention to use and ultimately the acceptance of information technology [1].

Perceived usefulness has a direct effect on users' attitudes toward use and it is the most important variable directly affecting intention to use. Perceived ease of use has a direct effect on attitudes toward use, and indirectly influenced attitudes toward use. Although the two factors, belief variables, have a major effect on attitudes toward use, perceived ease of use is less influential than perceived usefulness and confirms that there is a precedence relationship between two variables. And intention to use affects acceptance behavior. In addition, the validity and reliability of the scale of the two belief variables were secured and the elaboration of the measurement tools was promoted and the two variables proved to be consistent variables in various situations [1]. 


\section{Research Design}

\subsection{Research Model}

In this study, the TAM model, which is the Technology Acceptance Model (TAM), is used as a conceptual framework to select individual characteristics, service characteristics, and environmental factors as independent variables based on the previous studies described in Section 2. The purpose of this study is to examine the perceived usefulness of experienced services and the effect on mobile intention to use continuously. In addition, we set up the following research model to test whether there is a moderating effect on the influence of three independent variable factors and perceived usefulness of experienced service on the smart divide and income gap.

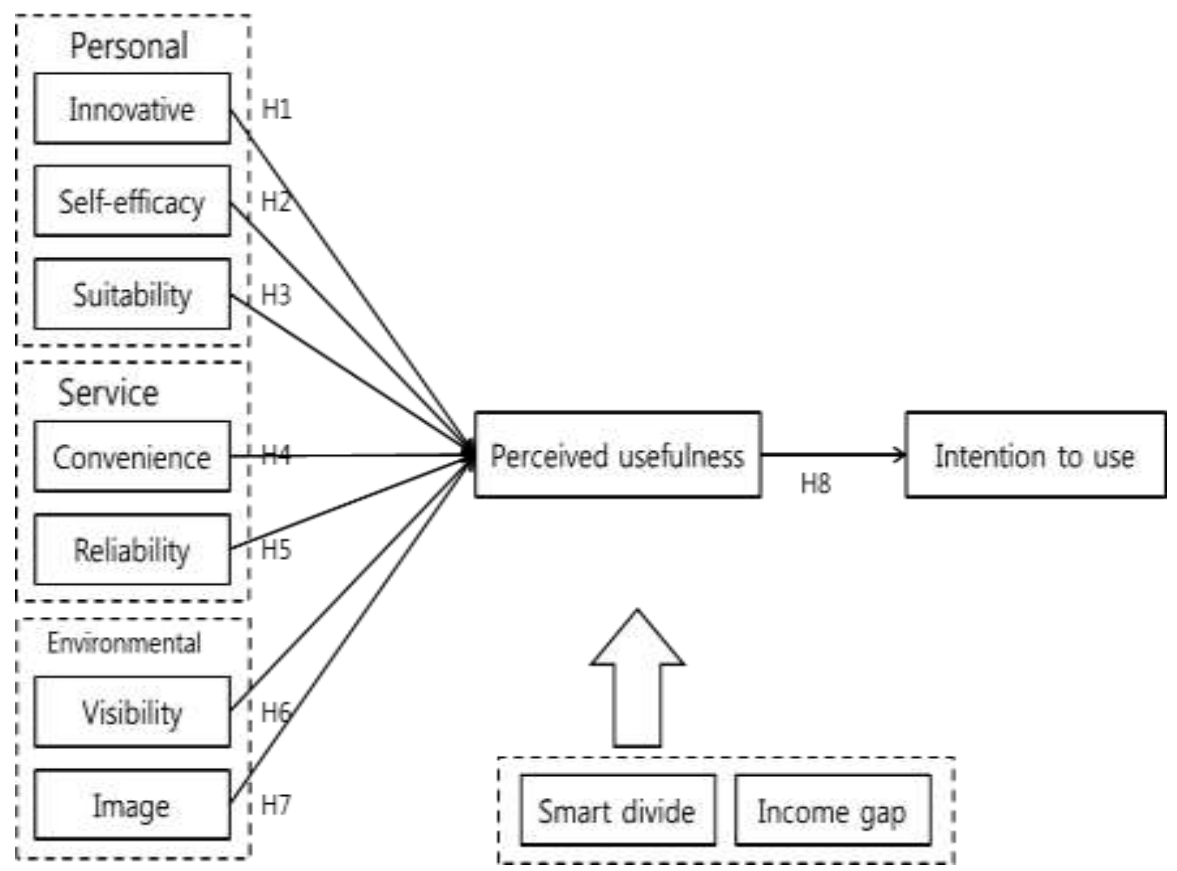

Figure 1. Research Model

\subsection{Personal Characteristics of FinTech Mobile Easy Payment Service}

Innovation refers to the degree of innovation of users who accept new ideas or knowledge [13]. Innovation is defined as the idea, practice, or thing that an individual or other adopting unit is perceived to be new, and diffusion is defined as the process by which an innovation communicates over time, through members of a social system, through a particular channel [2].

Self-efficacy can be defined as an individual's belief that he or she has the skills and abilities to perform a given task [3], which is distinct from general self-confidence and refers to a feeling confined to a particular domain.

Conformance refers to the degree to which the FIN-TECH mobile easy-to-use payment service is acceptable for the user for his / her work, lifestyle, value and demand.

Based on the related research, it is defined as the variables of the self-efficacy, innovation, and suitability of the user characteristics and the effect on perceived usefulness.

\subsection{Service Characteristics of FinTech Mobile Easy Payment Service}

The convenience of mobile payment system is a necessary condition to activate mobile shopping by providing payment whenever and wherever through mobile. The higher the 
degree to which a user learns how to use a product, the higher the value of a new product or service [4].

Reliability means the degree of trust in the FINTECH mobile easy payment service system [5].

The purpose of this study is to determine service characteristics as convenience and reliability variables based on related research and how they affect perceived usefulness.

\subsection{Environmental Characteristics of FinTech Mobile Easy Payment Service}

Visibility means the degree to which users of FINTECH mobile easy payment service are observed to use FinTech mobile easy payment service in the vicinity [14]. Visibility was measured by four items: the degree to which others felt they had seen what they were using, the degree to which they felt they had seen what they had used in their organization, the degree to which they felt they were easy to use, and the degree they felt they had used.

The image means the degree to which the use of the FinTech mobile easy payment service increases the image or status of the society [15]. The image was measured by four items: the degree to which I felt my use of images increased, the extent to which people around me thought of me as more worthwhile, and the degree of self-esteem.

Based on the related research, we define environment characteristics as image and visibility variables and investigate how they affect perceived usefulness.

\subsection{Perceived Usefulness and Intent to Use}

Perceived usefulness is the user's perception of the expected benefits of using smartphone payment services. It has been suggested that people are theorized about the perceived usefulness and ease of perceived use as the reason for accepting or rejecting information technology [1].

It is defined as the possibility that the attitude can lead to the behavior in the belief that the user's intention to use or the next action already planned before. In the early stages of information technology adoption, researchers who used intention to use information technology suggested that it is desirable to measure indirect use behaviors as intent rather than actual use [17].

\section{Empirical Analysis}

\subsection{Data Collection}

This study was conducted by surveying users who use FinTech mobile easy payment. First of all, the questionnaire items developed through the preliminary survey of experts in the Fintech mobile easy payment are used to determine whether the original questionnaire intentions can be appropriately conveyed to the respondents, whether the respondents can understand and respond to the questionnaire items properly. The reliability of the questionnaire was improved through the test. The online questionnaire was randomly selected and the questionnaire was conducted. Of these, 335 copies were collected for those who use FinTech Mobile Easy Payment. In addition, 150 questionnaires were collected through offline questionnaires, and a final analysis was conducted using a total of 414 questionnaires out of a total of 485 questionnaires, excluding 71 negative questionnaires.

A frequency analysis was conducted to determine the demographic characteristics of the study sample, and the results are shown in [Table 1]. 
Table 1. Demographic Data

\begin{tabular}{|c|l|l|l|}
\hline Variable & Category & \multicolumn{1}{|c|}{ Freq } & \multicolumn{2}{c|}{$\%$} \\
\hline \multirow{3}{*}{ Gender } & Male & 238 & 57.5 \\
\cline { 2 - 4 } & Female & 176 & 42.5 \\
\hline \multirow{4}{*}{ Age } & $<20$ & 16 & 3.9 \\
\cline { 2 - 4 } & $20 \sim 29$ & 64 & 15.5 \\
\cline { 2 - 4 } & $30 \sim 39$ & 117 & 28.3 \\
\cline { 2 - 4 } & $40 \sim 49$ & 104 & 25.1 \\
\cline { 2 - 4 } & $50 \sim 59$ & 67 & 16.2 \\
\cline { 2 - 4 } & $>60$ & 46 & 11.1 \\
\hline \multirow{2}{*}{$\begin{array}{c}\text { Marital } \\
\text { Status }\end{array}$} & Married & 244 & 58.9 \\
\cline { 2 - 4 } & Single & 170 & 41.1 \\
\hline
\end{tabular}

\subsection{Exploratory Factor Analysis and Reliability Analysis}

We conducted a feasibility analysis and a reliability analysis to test the appropriateness of the study model.

Validity refers to the concept of how precisely the concept is measured.

In this study, the abstract concept to be measured through the collected questionnaire adopts Construct Validity, which focuses on whether the proper measurement was made through the measurement tool, that is, whether the variance of the measurement value was indicated by the change of concept. An exploratory factor analysis was conducted for the validity test.

In this study, Cronbach's Alpha coefficients were used to test the internal consistency of the variables and the reliability was assessed based on the criterion that reliability was present when the Cronbach's Alpha coefficient was 0.7 or higher.

The results of exploratory factor analysis and reliability analysis were as shown in the following Table 2. Reliability analysis was conducted and as a result, factor loading value was analyzed as being more than 0.5 and Cronbach's Alpha coefficient was 0.7 or more. Appeared to be missing.

Table 2. The Result of Validity, Reliability Test of EFA

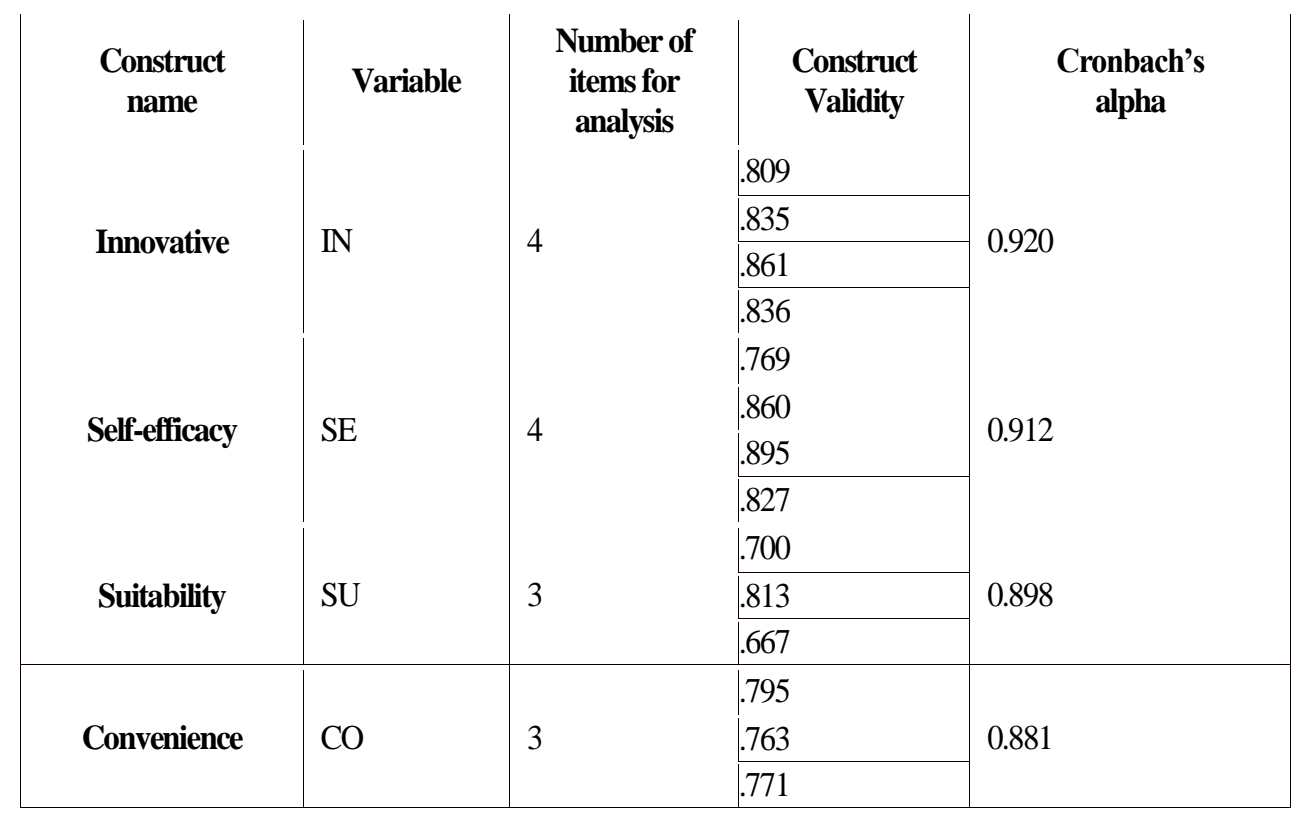




\begin{tabular}{|c|c|c|c|c|}
\hline \multirow{5}{*}{ Reliability } & \multirow{5}{*}{$\mathrm{RE}$} & \multirow{5}{*}{5} & .798 & \multirow{5}{*}{0.933} \\
\hline & & & 756 & \\
\hline & & & .775 & \\
\hline & & & .686 & \\
\hline & & & .755 & \\
\hline \multirow{3}{*}{ Visibility } & \multirow{3}{*}{$\mathrm{VI}$} & \multirow{3}{*}{3} & .731 & \multirow{3}{*}{0.876} \\
\hline & & & .850 & \\
\hline & & & .859 & \\
\hline \multirow{3}{*}{ Image } & \multirow{3}{*}{$\mathrm{IM}$} & \multirow{3}{*}{3} & .784 & \multirow{3}{*}{0.911} \\
\hline & & & .820 & \\
\hline & & & .742 & \\
\hline \multirow{4}{*}{$\begin{array}{l}\text { Perceived } \\
\text { usefulness }\end{array}$} & \multirow{4}{*}{$\mathrm{PE}$} & \multirow{4}{*}{4} & .737 & \multirow{4}{*}{0.848} \\
\hline & & & .584 & \\
\hline & & & 789 & \\
\hline & & & .719 & \\
\hline \multirow{4}{*}{$\begin{array}{l}\text { Intention } \\
\text { to use }\end{array}$} & \multirow{4}{*}{ US } & \multirow{4}{*}{4} & .593 & \multirow{4}{*}{0.894} \\
\hline & & & .687 & \\
\hline & & & 673 & \\
\hline & & & .688 & \\
\hline
\end{tabular}

\subsection{Confirmatory Factor Analysis}

The Confirmatory Factor Analysis (CFA), which is more accurate than the Exploratory Factor Analysis (EFA), can produce more precise results in reliability, validity, and single dimension. This is a statistical technique that is used for the purpose of verifying the validity test of the scale and the exploratory factor analysis model.

The exploratory factor analysis was applied to the items removed from exploratory factor analysis. The removed question items were removed after eliminating suitability (item 1, item 2), convenience (item 1), visibility (item 2), and image (item 4).

Because of the goodness of fit of the measurement model, we conducted intensive feasibility testing and conceptual reliability for the final selected items based on the results of confirmatory factor analysis. For the reliability and validity of the scale, it is ideal if the standardization factor is 0.7 or more. Construct Reliability, which measures the internal consistency of the indicator, is also 0.7 or more. Convergent Validity is the variance (Average Variance Extracted) should be at least 0.5.

Table 3. Convergent Validity Analysis

\begin{tabular}{|c|c|c|c|c|c|c|}
\hline Variable & Items & $\begin{array}{c}\text { Std. } \\
\text { Weights }\end{array}$ & C.R & $\mathbf{P}$ & CR & AVE \\
\hline \multirow{4}{*}{$\mathbf{I N}$} & 1 & 0.844 & & & \multirow{4}{*}{0.873} & \multirow{4}{*}{0.632} \\
\hline & 2 & 0.905 & 23.989 & $* * *$ & & \\
\hline & 3 & 0.888 & 23.257 & $* * *$ & & \\
\hline & 4 & 0.815 & 20.218 & $* * *$ & & \\
\hline \multirow{4}{*}{ SE } & 1 & 0.798 & & & \multirow{4}{*}{0.884} & \multirow{4}{*}{0.656} \\
\hline & 2 & 0.846 & 19.713 & $* * *$ & & \\
\hline & 3 & 0.94 & 22.495 & $* * *$ & & \\
\hline & 4 & 0.832 & 19.269 & $* * *$ & & \\
\hline SU & 3 & 0.887 & & & 0.813 & 0.593 \\
\hline
\end{tabular}




\begin{tabular}{|c|c|c|c|c|c|c|}
\hline & 4 & 0.776 & 19.905 & $* * *$ & & \\
\hline & 5 & 0.925 & 27.128 & $* * *$ & & \\
\hline \multirow{3}{*}{$\mathrm{CO}$} & 2 & 0.685 & & & \multirow{3}{*}{0.849} & \multirow{3}{*}{0.655} \\
\hline & 3 & 0.947 & 17.142 & $* * *$ & & \\
\hline & 4 & 0.915 & 16.897 & $* * *$ & & \\
\hline \multirow{5}{*}{$\mathbf{R E}$} & 1 & 0.822 & & & \multirow{6}{*}{0.918} & \multirow{6}{*}{0.677} \\
\hline & 2 & 0.832 & 20.296 & $* * *$ & & \\
\hline & 3 & 0.891 & 22.609 & $* * *$ & & \\
\hline & 4 & 0.881 & 22.205 & $* * *$ & & \\
\hline & 5 & 0.867 & 21.656 & $* * *$ & & \\
\hline \multirow{3}{*}{ VI } & 1 & 0.73 & & & & \\
\hline & 3 & 0.933 & 18.01 & $* * *$ & \multirow[t]{2}{*}{0.826} & \multirow[t]{2}{*}{0.616} \\
\hline & 4 & 0.866 & 17.371 & $* * *$ & & \\
\hline \multirow{3}{*}{ IM } & 1 & 0.912 & & & \multirow{3}{*}{0.860} & \multirow{3}{*}{0.673} \\
\hline & 2 & 0.958 & 32.524 & $* * *$ & & \\
\hline & 3 & 0.782 & 21.41 & $* * *$ & & \\
\hline \multirow{4}{*}{ PE } & 1 & 0.737 & & & \multirow{4}{*}{-0.833} & \multirow{4}{*}{0.558} \\
\hline & 2 & 0.661 & 13.099 & $* * *$ & & \\
\hline & 3 & 0.909 & 17.873 & $* * *$ & & \\
\hline & 4 & 0.789 & 15.776 & $* * *$ & & \\
\hline \multirow{4}{*}{ US } & 1 & 0.877 & & & \multirow{4}{*}{-0.843} & \multirow{4}{*}{0.575} \\
\hline & 2 & 0.718 & 17.312 & $* * *$ & & \\
\hline & 3 & 0.874 & 24.067 & $* * *$ & & \\
\hline & 4 & 0.836 & 22.214 & $* * *$ & & \\
\hline
\end{tabular}

\subsection{Validation of Discrimination}

Discriminant Validity means that there must be a clear difference in the measurements between different concepts and that the correlation between the potential variables obtained when measuring different concepts is low.

If there is a high correlation between latent variables, it means that there is a low discrimination between the two constituent variables.

In order to test discriminant validity, if the square root value of the mean variance extracted value for the measured variable is larger than the correlation between the conceptual variables, it is judged that there is discriminant validity between the variables [6].

Table 4 shows the correlation matrix between the concept of each variable and the square root of the mean variance extracted from each variable is larger than the correlation coefficient of each variable. There was no problem with the discrimination validity. 
Table 4. Convergent Validity Analysis

\begin{tabular}{|c|c|c|c|c|c|c|c|c|c|}
\hline & IN & SE & SU & CO & RE & VI & IM & PE & US \\
\hline IN & 0.795 & & & & & & & & \\
\hline SE & 0.261 & 0.810 & & & & & & & \\
\hline SU & 0.730 & 0.403 & 0.770 & & & & & & \\
\hline CO & 0.347 & 0.251 & 0.518 & 0.809 & & & & & \\
\hline RE & 0.468 & 0.379 & 0.83 & 0.506 & 0.823 & & & & \\
\hline VI & 0.266 & 0.262 & 0.512 & 0.398 & 0.435 & 0.785 & & & \\
\hline IM & 0.865 & 0.249 & 1.136 & 0.441 & 0.621 & 0.329 & 0.820 & & \\
PE & 0.345 & 0.323 & 0.516 & 0.347 & 0.473 & 0.317 & 0.365 & 0.747 & \\
\hline US & 0.572 & 0.49 & 1.041 & 0.488 & 0.748 & 0.479 & 0.747 & 0.572 & 0.758 \\
\hline
\end{tabular}

\subsection{Fit Test of Structural Equation Model}

Model Fitting is to know how well the model established by the researcher fits the data and is also called Model Testing. CFI, TLI, SRMR, and RMSEA are recommended as criteria for judging the goodness and badness of model fit [7].

Table 5. The Result of Model Fitness Test

\begin{tabular}{|c|c|c|c|}
\hline \multicolumn{2}{|c|}{ Fit indices } & \multirow{2}{*}{$\begin{array}{c}\text { Indicator } \\
1300.008 \\
(\mathrm{P}=0.000)\end{array}$} & \multirow{2}{*}{$\begin{array}{r}\text { Desirable } \\
\mathrm{p} \leqq 0.05^{\sim} 0.10\end{array}$} \\
\hline \multirow{7}{*}{$\begin{array}{l}\text { Absolute fit } \\
\text { index }\end{array}$} & $x^{2}(C M I N) p$ & & \\
\hline & $x^{2}(C M I N) / d f$ & 2.796 & $1.0 \leqq \mathrm{CMIN} / \mathrm{df} \leqq 2.0 \sim 3.0$ \\
\hline & RMSEA & 0.078 & $\leqq 0.05^{\sim} 0.08$ \\
\hline & RMR & 0.0707 & $\leqq 0.08$ \\
\hline & GFI & 0.815 & $\geqq 0.8 \sim 0.9$ \\
\hline & AGFI & 0.777 & $\geqq 0.8 \sim 0.9$ \\
\hline & PGFI & 0.675 & $\geqq 0.5^{\sim} 0.6$ \\
\hline \multirow{3}{*}{$\begin{array}{l}\text { Incremental } \\
\text { Fit index }\end{array}$} & NFI & 0.893 & $\geqq 0.8 \sim 0.9$ \\
\hline & NNFI(TLI) & 0.918 & $\geqq 0.8 \sim 0.9$ \\
\hline & $\mathrm{CFI}$ & 0.928 & $\geqq 0.8 \sim 0.9$ \\
\hline \multirow{2}{*}{$\begin{array}{c}\text { Parsimony } \\
\text { Fit index }\end{array}$} & PNFI & 0.787 & $\geqq 0.6$ \\
\hline & PCFI & 0.817 & $\geqq 0.5^{\sim} 0.6$ \\
\hline
\end{tabular}

\subsection{Verification of Research Model}

To analyze the effects of the hypotheses on this study, path analysis was conducted. Seven of the eight hypotheses were adopted and one hypothesis was rejected. The results of the hypothesis test are summarized in Figure 2. See Table 6. If you want to know the independent variables that have a greater impact, use a standardized regression weight that 
takes into account relative importance. Standard Error (S.E.) means the accuracy (stability) of the other number. The adoption of the hypothesis is judged based on the criteria of C.R. (Critical Ratio) value of \pm 1.96 or more and the significance level value (P-Value) of 0.05 or less.

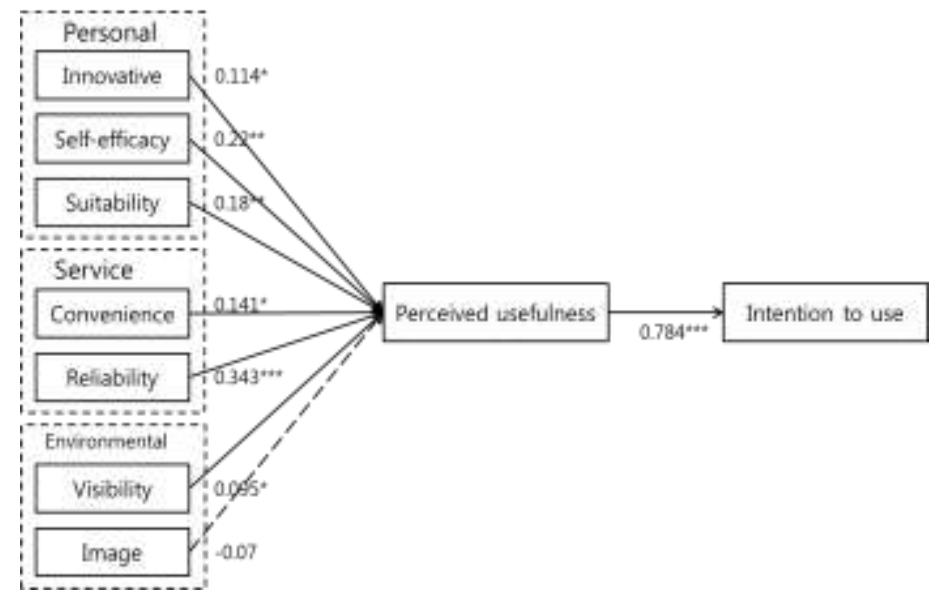

Figure 2. The Result of Hypothesis Test

Table 6. The result of Path Analysis

\begin{tabular}{|c|c|c|c|c|c|c|}
\hline \multicolumn{2}{|c|}{ Hypothesis } & \multirow{2}{*}{$\begin{array}{c}\text { Standardized } \\
\text { Estimate }\end{array}$} & \multirow{2}{*}{ S.E. } & \multirow{2}{*}{ C.R } & \multirow{2}{*}{ P-value } & \multirow{2}{*}{ Results } \\
\hline & $\leftarrow$ & & & & & \\
\hline \multirow{7}{*}{$\mathbf{P E}$} & IN & 0.114 & 0.035 & 2.249 & 0.025 & $\mathrm{O}$ \\
\hline & SE & 0.22 & 0.04 & 4.931 & $* * *$ & $\mathrm{O}$ \\
\hline & SU & 0.18 & 0.04 & 2.651 & 0.008 & $\mathrm{O}$ \\
\hline & $\mathrm{CO}$ & 0.141 & 0.049 & 2.637 & 0.008 & $\mathrm{O}$ \\
\hline & $\mathrm{RE}$ & 0.343 & 0.053 & 5.145 & $* * *$ & $\mathrm{O}$ \\
\hline & VI & 0.095 & 0.042 & 1.968 & 0.049 & $\mathrm{O}$ \\
\hline & $\mathrm{IM}$ & -0.07 & 0.036 & -1.143 & 0.253 & $X$ \\
\hline US & PE & 0.784 & 0.079 & 13.901 & $* * *$ & $\mathrm{O}$ \\
\hline
\end{tabular}

As a result of the research hypothesis tested, the results of the hypothesis affecting the perceived usefulness of the three factors such as individual personality (innovation, self efficacy, and suitability) are influenced by innovation, self - efficacy, and suitability. The results showed that self - efficacy, fitness, and innovation were the most influential factors.

Second, the results of the hypotheses that affect the perceived usefulness of the service experienced by the two factors, such as service characteristics (convenience and reliability), showed that convenience and reliability were influential. When analyzed, the reliability and convenience were revealed.

Third, the results of the hypotheses that affect the perceived usefulness of the service experienced by the two factors such as the environmental characteristics (visibility and the image) showed that the visibility influenced the image, but the image doesn't affect the perceived usefulness of the experienced service. 


\subsection{Moderating Effects Analysis}

The control effect means that the relationship between the dependent variable and the independent variable varies in size and direction according to the third variable. This third variable is called the moderating variable. A third independent variable that affects the relationship between independent and dependent variables is called the regulatory variable. In general, regulatory variables have properties that do not change significantly over time.

The results of the research hypotheses were derived, and the moderating effect was analyzed to see how the hypotheses differ according to the smart divide and income level. As for the analysis method, the difference between the groups was confirmed individually through the pairwise parameter comparison, and whether there was a difference between the groups was judged by the Critical Ratios for Differences between Parameters (ZStatistics).

Table 7. Smart Divide Group Hypothesis

\begin{tabular}{|c|c|c|c|c|}
\hline \multirow{3}{*}{$\begin{array}{c}\text { Dependant } \\
\text { Variable }\end{array}$} & \multirow{3}{*}{$\begin{array}{c}\text { Independent } \\
\text { variable }\end{array}$} & \multicolumn{2}{|c|}{ Group } & \multirow{3}{*}{$\begin{array}{c}\text { Critical Ratio } \\
\text { for } \\
\text { Differences } \\
\text { Between } \\
\text { Parameters }\end{array}$} \\
\hline & & $\begin{array}{c}\mathbf{A} \\
(\mathbf{n}=\mathbf{2 3 3})\end{array}$ & $\begin{array}{c}\text { B } \\
(n=181)\end{array}$ & \\
\hline & & $\begin{array}{c}\text { standardized } \\
\text { Estimate }\end{array}$ & $\begin{array}{c}\text { standardized } \\
\text { Estimate }\end{array}$ & \\
\hline \multirow{6}{*}{ PE } & IN & 0.039 & $0.222 * *$ & $\begin{array}{l}-4.184 * * * \\
\text { (difference) }\end{array}$ \\
\hline & SE & $0.348 * * *$ & $0.134 *$ & $\begin{array}{l}-4.332 * * * \\
\text { (difference) }\end{array}$ \\
\hline & SU & 0.172 & $0.227^{*}$ & $\begin{array}{l}-2.400 * * \\
\text { (difference) }\end{array}$ \\
\hline & $\mathrm{CO}$ & 0.069 & $0.170^{*}$ & $\begin{array}{l}1.163 \\
\text { (No } \\
\text { difference) }\end{array}$ \\
\hline & RE & $0.279 * *$ & $0.311 * *$ & $\begin{array}{l}-1.490 \\
\text { (No } \\
\text { difference) }\end{array}$ \\
\hline & VI & 0.147 & 0.126 & $\begin{array}{l}-0.246 \\
\text { (No } \\
\text { difference) }\end{array}$ \\
\hline US & PE & $0.709 * * *$ & $0.828 * * *$ & $\begin{array}{l}5.663 * * * \\
\text { (difference) }\end{array}$ \\
\hline
\end{tabular}

The ability to utilize mobile easy payment services may be different depending on the smart divide in the use of FinTech-based mobile easy payment service. In order to confirm the possibility of expectation difference for mobile easy payment service, we divided into 233 people with low mobile smart device useability (A group) and 181 people with high mobile smart device useability (B group). As shown in Table 7, the relationship between innovativeness, self-efficacy, and perceived usefulness is affected by the difference test statistic $-4.184 * * *,-4.332 * * *,-2.400 * *$ between group A and group B. In addition, the perceived usefulness of the experienced service influences the Intent to use of service, and the difference test statistic is $5.663 * * *$. 
Table 8. Income Gap Group Hypothesis

\begin{tabular}{|c|c|c|c|c|}
\hline \multirow{3}{*}{$\begin{array}{c}\text { Dependant } \\
\text { Variable }\end{array}$} & \multirow{3}{*}{$\begin{array}{l}\text { Independent } \\
\text { variable }\end{array}$} & \multicolumn{2}{|c|}{ Group } & \multirow{3}{*}{$\begin{array}{c}\text { Critical Ratio } \\
\text { for } \\
\text { Differences } \\
\text { Between } \\
\text { Parameters }\end{array}$} \\
\hline & & $\underset{(n=202)}{A}$ & $\underset{(n=212)}{B}$ & \\
\hline & & $\begin{array}{l}\text { standardized } \\
\text { Estimate }\end{array}$ & $\begin{array}{l}\text { standardized } \\
\text { Estimate }\end{array}$ & \\
\hline \multirow{6}{*}{ PE } & IN & -0.041 & $0.294 * * *$ & $\begin{array}{l}-2.464 * * \\
\text { (difference) }\end{array}$ \\
\hline & SE & $0.257 * * *$ & $0.201 * * *$ & $\begin{array}{l}-3.457 * * * \\
\text { (difference) }\end{array}$ \\
\hline & SU & $0.281 * *$ & 0.046 & $\begin{array}{l}-2.822 * * \\
\text { (difference) }\end{array}$ \\
\hline & $\mathrm{CO}$ & 0.117 & 0.121 & $\begin{array}{l}1.710 \\
\text { (No difference) }\end{array}$ \\
\hline & RE & $0.268^{* *}$ & $0.438 * * *$ & $\begin{array}{l}1.155 \\
\text { (No difference) }\end{array}$ \\
\hline & VI & 0.122 & 0.086 & $\begin{array}{l}-1.151 \\
\text { (No difference) }\end{array}$ \\
\hline US & $\mathrm{PE}$ & $0.80 . * * *$ & $0.778 * * *$ & $\begin{array}{l}7.155^{* * *} \\
\text { (difference) }\end{array}$ \\
\hline
\end{tabular}

In order to confirm the possibility of group differences according to the income gap, we divided into 202 groups with monthly income less than 4 million won (A group) and 212 persons with monthly income more than 4 million won (B group). As shown in Table 8, the effect of innovativeness, self-efficacy, and suitability variables on perceived usefulness was more significant in group A than group B, the difference test statistics are $-2.464 * *,-3.457$ $* * *,-2.822 * *$. Finally, it was found that the group B was more sensitive to the difference test statistic $7.155 * * *$ in the effect of the perceived usefulness of the service experienced on intention to use.

\section{Conclusion}

With the advent of smartphones, we have come to the age when each individual is connected to the Internet from anywhere, regardless of time, and receives the service they desire in all fields of finance, shopping, public, politics, education and so on. In most consumption activities, payment is inevitable, and new payment methods that break down traditional methods such as cash, account transfer, and credit cards have emerged in this payment method. This study is a kind of exploratory study on what kind of policy measures are necessary for mobile easy payment service which is required as a payment service infrastructure essential for consumption activity of the future society according to the trend of the times, this is an empirical study of the factors affecting the continuous use and diffusion of payment services. The purpose of this study is to investigate the factors affecting the continuous use intention of mobile easy payment service for the general public who have experience using mobile easy payment service.

First, the perceived usefulness has a great influence on the intention of continuous use. This can be seen as the willingness of users to use mobile payment service continuously when they feel useful about the easy payment service that they use.

Second, innovation, self-efficacy, and suitability as personal characteristics all affected perceived utility. This is because people who have innovative tendencies feel more usefulness, higher self-efficacy feel more usefulness, and they can be judged to be more aware of their usefulness as they think fit in their own consumption patterns. 
Third, convenience and reliability as service characteristic variables all affected perceived usefulness. The convenience measured here is not a measure of ease of use, and it is convenient to use it regardless of the time of day. It is believed that the higher the reliability of the service itself as well as the service itself, the more useful it is.

Fourth, visibility as an environmental characteristic variable affects perceived usefulness, but the image does not affect perceived usefulness. Visibility means that mobile casual payment services are widely used in the surrounding social environment. As visibility has an important influence on the intention to use a smartphone, it means that you feel more useful. On the other hand, the original hypothesis was rejected as the image does not affect perceived usefulness. This means that the user does not feel that the service is useful because of the self-esteem of the user using the mobile easy payment service, or the impression of the gaze that others view the user.

The purpose of this study is to find out the difference between the various layers while studying the intention of continuous use of the mobile easy payment service. It is not related to the characteristic variable or the environmental characteristic variable but is closely related to the personal characteristic variable. The proliferation of mobile easy payment services shows that individual-focused efforts are needed rather than improvement of the service itself or socio-environmental efforts. Finally, we could find the necessary policy support factors to move into a society without coins or cashless society in the future. It is very important for the nation to set up and implement support policies to overcome the phenomenon of a smart divide between tiers that are emerging as the spread of smart phones is becoming more and more important. For example, there is a need for education and training for those who are not able to utilize smartphones and a policy of providing support for vulnerable groups that cannot access smartphones. And it was confirmed that finding the support policies that promote the use of mobile easy payment service to the people with low incomes due to the difference in income gap is very important factor in the future spread of mobile easy payment service.

The difference in the degree of use of the hierarchies due to the smart divide or the income gap is not related to the service characteristic parameter or the environmental characteristic parameter of the mobile easy payment service but is closely related to the individual characteristic parameter. The proliferation of mobile easy payment services shows that individual-focused efforts are needed rather than the improvement of the service itself or the socio-environmental effort.

Through this research, we could find the necessary policy support factors to move into a society without coins or cashless society. It is very important for the nation to set up and implement support policies to overcome the phenomenon of a smart divide between tiers that are emerging as the spread of smartphones is becoming more and more important. For example, it is needful to pay for the vulnerable classes that need learning and education at the level where the smartphone is not able to use any smartphone is not accessible, and it will contribute to the spread of FinTech mobile payment service.

\section{Acknowledgment}

This paper is a revised and expanded version of a paper entitled "A Study on the Intention to Use of Fintech-based Mobile Easy Payment Service" Presented at [13th International Convergence Workshop, Jeju National University and 8.20 22].

\section{References}

[1] F. D. Davis, "Perceived usefulness, perceived ease of use, and user acceptance of information technology", MIS Quarterly, (1989).

[2] E. M. Rogers, "Diffusion of Innovations", 5th edition, Free Press, (2003).

[3] A. Bandura, "Self-efficacy; Toward a Unifying Theory of Behavioral Change", Psychological Review, vol. 84, no. 2, (1977), pp. 191-215. 
[4] R. L. Thompson, C. A. Higgins and J. M. Howell, "Personal Computing: Toward a conceptual Model of Utilization", MIS Quarterly, vol. 15, no. 1, (1991), pp. 125-143.

[5] T. T. T. Pham and J. C. Ho, "The Effects of Product-Related, Personal-Related Factors and Attractiveness of Alternatives on Consumer Adoption of NFC-based Mobile Payments", Technology in Society, vol. 43, (2015), pp. 1-16.

[6] C. Fornell and D. F. Larcker, "Evaluating Structural Equation Models with Unobservable Variables and Measurement Error", Journal of Marketing Research, vol. 18, no. 1, (1981), pp. 39-50

[7] J. F. Hair Jr., W. C. Black, B. J. Babin and R. E. Anderson, "Multivariate Data Analysis", 7th edition, pearson Hall, (2010).

[8] F. D. Davis, "User acceptance of Information technology: system characteristics, user perception and behavioral impacts", International journal of man-machine studies, vol. 38, no. 3, (1993), pp. 475-487.

[9] G. Chandrika, "Study on Software Reliability and Reliability Testing", Asia-pacific Journal of Convergent Research Interchange, HSST, ISSN: 2508-9080, vol. 1, no. 1, (2015) March, pp. 7-20.

[10] R. Peddigari, "Impact of User Ratings on Mobile Apps Due Fault and Change Proneness in API", Asiapacific Journal of Convergent Research Interchange, HSST, ISSN: 2508-9080, vol. 1, no. 2, (2015) June, pp. 43-59.

[11] J. Hyun Kim and R. Sekhar Reddy, "Implementation of Mobile Apps Across Globe and Challenge to Software Engineering", Asia-pacific Journal of Convergent Research Interchange, HSST, ISSN: 25089080, vol. 1, no. 3, (2015) September, pp. 1-16.

[12] J. Hee Lee and K. Raj, "Hybrid Data Management in Cloud Security", Asia-pacific Journal of Convergent Research Interchange, HSST, ISSN: 2508-9080, vol. 1, no. 4, (2015) December, pp. 33-39

[13] A. Udayini, "An Approach for Routing Queries in P2P Networks", Asia-pacific Journal of Convergent Research Interchange, HSST, ISSN: 2508-9080, vol. 2, no. 1, (2016), pp. 7-12.

[14] L. Krishna, "Authenticated Searching Multi Key word in the Cloud Computing”, Asia-pacific Journal of Convergent Research Interchange, HSST, ISSN: 2508-9080, vol. 2, no. 1, (2016) March, pp. 29-36.

[15] T. Sai Raaga Sowmya, "Cost Minimization for Big Data Processing in Geo-Distributed Data Centres", Asia-pacific Journal of Convergent Research Interchange, HSST, ISSN: 2508-9080, vol. 2, no. 4, (2016) December, pp. 33-41

[16] M. Bansal and L. Shricastava, "Performance Analysis of Wireless Mobile Adhoc Network with Different Types of Antennas", HSST, ISSN: 2508-9080, vol. 3, no. 1, (2017) March, pp. 33-44

[17] M. lgbaria and J. Livari "The effects of self-efficacy on computer usage", Omega, vol. 23, no. 6, (1995), pp. 587-605

\section{Authors}

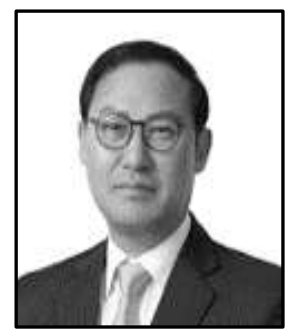

Hong-Jae Lee, He graduated from Seoul National University in Korea and received a master's degree in statistics (1985) and a doctorate in engineering (2017). He has been working in the IT field for about 30 years and is now CEO of Smartro, the payment service company. He is interested in IT, FinTech, and industry convergence.

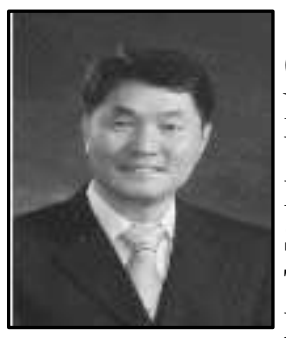

Kyeong-Seok Han, received his bachelor's degree of Education (1979) and master's degree of Management (1984) in Seoul National University, and doctor's degree of MIS in Purdue University, USA (1989). He was a professor of University of Houston. Now he is a professor in the Dept. of Management, Soongsil University, Seoul, Korea. His research interests focus on Technical MIS, Digital Economy, Agent-Eased Simulation, Web Programming, ERP. 
International Journal of Advanced Science and Technology

Vol.116 (2018) 